ISSN: 0213-2052 - eISSN: 2530-4100

DOI: http://dx.doi.org/10.14201/shha2019376394

\title{
LA PRODUCCIÓN DE MONEDA PROVINCIAL JULIO-CLAUDIA EN EL AFRICA PROCONSULARIS
}

\section{The Julio-Claudian Provincial Coinage Production in Africa Proconsularis}

\author{
Helena GOZALBES GARCÍA \\ Universidad de Granada \\ helenagg@ugr.es
}

Fecha de recepción: 13-9-2018; aceptación definitiva: 27-4-2019

ORCID: 0000-0002-5949-3634

RESUMEN: El objetivo del presente trabajo es analizar los distintos aspectos financieros de las acuñaciones emitidas por las diversas cecas

1. El presente trabajo se ha elaborado en el marco del proyecto de estancia de investigación doctoral "Los emblemas monetarios en el Imperio romano, expresando las identidades provinciales desde realidades locales, regionales y globales", inserto dentro del Programa de Doctorado en "Historia y Artes" de la Universidad de Granada, desarrollado entre marzo y junio de 2018 en la University of Leicester, el Bristish Museum y el Ashmolean Museum, financiado por el Vicerrectorado de Investigación y Transferencia de la Universidad de Granada y tutorizado por los profesores Ángel Padilla Arroba y David Mattingly. Les agradezco enormemente sus constantes consejos y correcciones, así como el desinteresado e inestimable ánimo y apoyo que vienen prestando a lo largo de la investigación doctoral que ha dado lugar a la presente contribución, la cual, en todo caso, se presenta bajo mi responsabilidad. Agradezco igualmente a Christopher Howgego y Jerome Mairat, conservadores del Ashmolean Museum, el permiso y las facilidades procuradas durante el estudio de la moneda provincial julio-claudia depositada en la mencionada institución, pues además sin la ayuda prestada por ambos no hubiera sido posible la realización del mismo. 
africanas que estuvieron en actividad en época de acuñación provincial. Para lograr este objetivo, se presenta un estudio de la producción monetaria de estos centros emisores. Así, en una primera parte, se relacionan los volúmenes de emisión por centro y por época de fabricación y, en una segunda parte, se consideran los volúmenes de acuñación por valor monetario. El detenido análisis y cotejo de estos datos con la información correspondiente a otros fenómenos de acuñación monetaria provincial coetánea, ha permitido que, en una tercera parte del trabajo, se plantee una aproximación acerca de las posibles intenciones financieras de las que pudieron disponer las emisiones provinciales africanas, sin obviar que aquéllas pudieron además obedecer a otras múltiples funciones no exclusivamente económicas.

Palabras clave: Numismática; África; provincias romanas; Augusto; Carthago.

ABSTRACT: The aim of this paper is to analyze the divers financial aspects of the coinages issued by the severals African mints that were active in times of provincial minting. To achieve this objective, we present a study of the monetary production of these centers. In a first part, we have tried to relate the emission volumes by center and by time of manufacture and, in a second part, we have also taken into account the coinage volumes by monetary value. The detailed analysis and comparison of these data, in relation to the information corresponding to other phenomena of provincial monetary coinage, has allowed us, in a third part of the work, to propose an approximation about the possible financial intentions that the African provincial emissions had, without forgetting that these could also be due to other multiple functions not exclusively economic.

Keywords: Numismatics; Africa; Roman provinces; Augusto; Carthago.

\section{Planteamientos iniciales}

La moneda provincial africana, a menudo también denominada colonial, cívica, ciudadana o latina, fue aquella emitida de manera oficial por algunas ciudades del África Proconsular en los primeros años de la etapa imperial romana, coincidiendo con los periodos de imperio de Augusto y Tiberio. Por tanto, las series africanas fueron puestas en circulación en los momentos inmediatamente posteriores a la creación de la provincia. Este fenómeno monetario se engloba dentro de una producción mucho más general, no exclusiva del territorio objeto de estudio, que se registró en un gran número de ciudades del Imperio romano durante un periodo mucho más amplio de tiempo que el constatado para los propios centros 
africanos. Debe recordarse que a nivel general, en determinadas zonas, las emisiones de moneda provincial se iniciaron en la segunda mitad del siglo I a. C. y, en algunas otras se extendieron hasta el final del siglo III d. C. Es más, este fenómeno de acuñación con control básicamente local tampoco fue totalmente privativo de la época en la que particularmente se desarrolló. A juzgar por las características del mismo, puede considerarse como la continuación de una tradicional práctica de producción de moneda, especialmente en bronce ${ }^{2}$, desarrollada por parte de un gran número de ciudades que con posterioridad se irán incluyendo en el Imperio.

No obstante, las emisiones provinciales no fueron las únicas acuñaciones que se emitieron y emplearon en aquellos momentos. Junto a ellas se pusieron en circulación otro tipo de piezas conocidas generalmente como imperiales o estatales. Estas emisiones, a diferencia de lo que se advierte con respecto a las series cívicas, se fabricaron con la intención de hacer frente a los distintos requerimientos de numerario que precisaba el Estado romano y, por ello, en ocasiones además de presentar diversas marcas alusivas al control central al que estaban sujetas, se beneficiaron de una circulación habitualmente mucho más extendida en el espacio y quizás en el tiempo que las acuñadas en el seno de las ciudades.

Teniendo en cuenta todas estas circunstancias, en el presente trabajo se ha intentado exponer un detenido y preciso estudio acerca de los aspectos financieros que caracterizaron el conjunto de monedas provinciales producidas por las cecas del África Proconsular ${ }^{3}$ analizado en el contexto monetario de su propia fabricación. Por este motivo, a lo largo de las líneas que siguen analizaremos el fenómeno de acuñación provincial africano y sus particularidades en relación a la general práctica de emisión

2. BurnetT, A.: "The Augustan Revolution seen from the mints of the province", Journal of Roman Studies, 101, 2011, p. 2.

3. Para la realización de este trabajo se ha revisado la información contenida en el catálogo general de referencia sobre moneda provincial (BurnetT, M., AmAndRY, M. \& Ripollès, P. P.: Roman Provincial Coinage, vol. I. From the death of Caesar to the death of Vitellius (44BC-AD 69). London-Paris, 1992 (citado como RPC) y sus sucesivos suplementos (Burnett, A., Amandry, M. \& Ripollès, P. P.: Roman provincial coinage. Supplement 1. London-Paris, 1998 (citado como RPC-S); Burnett, A., Amandry, M., Ripollès, P. P. \& CARRADICE, I.: Roman provincial coinage. Supplement 2. Valencia, 2006 (citado como RPCS2); Burnett, A, Amandry, M., Carradice, I., Ripollès, P. P. \& Spoerri Butcher, M.: Roman provincial coinage. Supplement 3. New York, 2014 (citado como RPC-S3); BuRnetT, A., Amandry, M., Hostein, A., Mairat, J., Ripollès, P. P. \& Spoerri Butcher, M.: Roman provincial coinage. Supplement 4. Oxford, 2017 (citado como RPC-S4); AMANDrY, M., BurnetT, A., Hostein, A., Mairat, J., Ripollès, P. P. \& Spoerri Butcher, M.: Roman provincial coinage. Supplement 5. Oxford, 2019). Presentamos únicamente el estudio de las piezas que han sido adscritas sin ninguna duda al periodo de acuñación provincial. 
monetaria ciudadana. En el presente trabajo, se ha considerado como fundamento inicial que el estudio de la moneda batida por estas ciudades, en confrontación a la acuñada por otros centros, puede constituir una sugestiva aportación para intentar analizar algunos de los elementos económicos que caracterizaron la sociedad en la que se hubo de fabricar, pues contribuye a entender cuáles fueron las causas y las funciones a las que estaban destinadas. Y es que, pese a que somos también de la opinión de que los desencadenantes de la emisión de una determinada serie monetaria no siempre se relacionaron con circunstancias puramente financieras, creemos que resulta también bastante obvio que, por lo general, aquellas afectaron de manera muy manifiesta.

Por otra parte, el trabajo que se presenta también se fundamenta en la escasez de estudios detallados sobre las series provinciales africanas ${ }^{4}$, en contraste sobre todo con los numerosos análisis sobre las emisiones acuñadas con anterioridad de los que en la actualidad se dispone. El trabajo de L. Müller ${ }^{5}$, publicado en el año 1861, centró la atención sobre las producciones africanas emitidas en distintos momentos, abordando someramente el tema. De hecho, aunque el autor manejó muchos menos datos de los que en la actualidad se disponen, su trabajo tuvo una gran relevancia en los estudios de la Numismática antigua del Norte de África. Hasta tal punto fue así que el mismo ha sido generalmente tenido en cuenta por los investigadores posteriores.

Ahora bien, pese a lo mencionado, las monedas africanas sí han sido frecuentemente analizadas como fenómenos particulares en los diversos trabajos que sobre numismática provincial se han venido publicando ${ }^{6}$. En este sentido, cabría referir que más allá de la labor realizada por los distintos departamentos y gabinetes numismáticos en cuanto a la propia identificación y catalogación de las piezas7 y la esporádica mención de las

4. Callegarin, L., Frey-Kupper, S. et Geneviève, V.: "Les monnayages provinciaux: les provinces occidentales", en Arnold-Biucchi, C. \& Caccamo Caltabiano, M. (eds.): A survey of numismatic reseach 2008-2013. Taormina, 2015, p. 243.

5. Müller, L.: Numismatique de l'ancienne Afrique, II: les monnaies de la Syrtique, de la Byzacène et de la Zeugitane. Bologna, 1861.

6. BurnetT, A.: Coinage in the Roman World, London, 1987; Id.: "Roman Provincial Coins of the Julio-Claudians", en Essays in Honour of R. Carson and G. K. Jenkins. London, 1993; Id.: 2011; Id.: "Monetary union in the Roman Empire", Numismatikai közlöny, 100101, 2001-2002; Grant, M.: From Imperium to Auctoritas. Cambridge, 1946; MatTingly, H.: "The Provincial and Local Coinage of the Early Empire", en Roman Coins. London, 1977.

7. La publicación de catálogos numismáticos con presencia de emisiones provinciales africanas es muy amplia. Sin entrar en una enumeración muy extensa, nos referimos a corpus fundamentales como son sobre todo el de J. Mazard (Mazard, J.: Corpus Nummorum Numidiae Mauretaniaque. Paris, 1955) y el de G. K. Jenkins (Jenkins, G. K: Sylloge 
HELENA GOZALBES GARCÍA

LA PRODUCCIÓN DE MONEDA PROVINCIAL JULIO-CLAUDIA

EN EL AFRICA PROCONSULARIS

mismas en algunos trabajos sobre temas numismáticos diversos ${ }^{8}$, resultan estimables los resultados de las investigaciones desarrolladas por dos autores principalmente. De un lado, J. Alexandropoulos, quien muy recientemente ha dado a conocer una serie de trabajos que tratan de valorar las dinámicas socio-culturales relacionadas con el monetario antiguo africano ${ }^{9}$ y que nosotros consideramos fundamentales para cualquier investigación que trate de acercarse al conocimiento de estas particulares emisiones. De otro lado, M. Amandry, quien también en los últimos años ha publicado diversas aportaciones esenciales, en este caso, dado que presentan el estudio específico de determinadas cecas del África Proconsular y la enumeración de las series monetarias puestas en circulación por las mismas ${ }^{10}$. Precisamente, estas seriaciones fueron las que se incorporaron ligeramente actualizadas al volumen correspondiente del Roman Provincial Coinage ${ }^{11}$.

Nummorum Graecorum. Danish National Museum, North Africa, Syrtica-Mauretania. Copenhangen, 1969), y otros centrados en el monetario provincial romano, muy especialmente el de A. Burnett, M. Amandry y P. P. Ripollès (BurnetT, A, Amandry, M. \& Ripollès, P. P.: 2006, pp. 182-209).

8. Entre ellos, por ejemplo, los recientes de F. Hurlet y A. Suspène (HuRlet, F. et Suspène, A.: "Le proconsul et le Prince. À propos des portraits monétaires des proconsuls d'Africa et d'Asia sous le Principat d'Auguste", en Baudry, R. et Destephen, S. (eds.): La societé romaine et ses élites. Hommages à Elisabeth Deniaux. Paris, 2012) y de V. Györi (GYÖRI, V.: "The lituus and augustan provincial coinage", Acta antiqua Academiae Scientiarum Hungaricae, 55, 2015).

9. AleXANDROPOlous, J.: "La romanisation des monnayages antiques de l'Afrique du Nord orientale: Analyse de quelques jalons", en García-Bellido, M. P. y Callegarin, L. (coords.): Los cartagineses y la monetización del Mediterráneo Occidental. Madrid, 2000; Id.: Les monnaies de l'Afrique antique. 400 av.J.-C.-40 ap.J.-C. Toulouse-Le Mirail, 2007; Id.: "Monnaie", Encyclopédie berbère, 32, 2010.

10. AmandRY, M.: "Le monnayage augustéen de Leptis Minor (Byzacène)", Schweizer Münzblätter, 33-37, 1983; Id.: "Notes de numismatique africaine II", Revue Numismatique, 28, 1986; Id.: "Notes de numismatique africaine III", Revue Numismatique, 30, 1988; Id.: "Notes de numismatique africaine V", Revue de Numismatique, 32, 1990; Id.: "Notes de numismatique africaine. VI. 8. Achulla", Revue de Numismatique, 34, 1992; Id.: "Le monnayage de Thaena/Thena", en Lancel, S. (ed.): Africa du Nord Antique et médievale. Numismatique, langues, écritures et arts du peregrina, spécifité des arts figurés. Actes di VIIe coll. Int. Sur l'Histoire et l'Archéologie de l'Afrique du Nord. Paris, 1995; Id.: "Une monnaie inédite d'Auguste frappé à Colonia Iulia Paterna", en DelrieuX, F. et KaYser, F. (eds.): Des déserts d'Afrique au pays des Allobroges. Mélanges offerts à Francois Bertrandy. Chambéry, 2010.

11. Burnett, M., Amandry, M. \& Ripollès, P. P.: 2006, pp. 182-209. 


\section{El Auge De los talleres PROVINCIALES AFriCANOS EN ÉPOCA AUGUSTEA}

La producción de moneda provincial afectó de modo más o menos intenso y regular a más de 400 ciudades dispersadas por todas las provincias romanas, fomentándose especialmente en centros que se asociaban a ciudades privilegiadas desde el punto de vista jurídico. La mayor parte de los talleres se encontraban relacionados con colonias o municipios, mientras que los ejemplos de cecas ligadas a otro tipo de civitates $^{12}$ fueron menos numerosos. Este hecho ha llevado a algunos investigadores a relacionar directamente el fenómeno de acuñación monetaria cívica con el proceso de fundación de algunas colonias y la promoción jurídica municipal de centros preexistentes señalando que el primero podría haber sido resultado del segundo. Así de hecho se ha constatado en provincias como las hispanas ${ }^{13}$.Ahora bien, pese a que como se advierte generalmente las ciudades emisoras de monetario provincial habituaban a asociarse con ciudades favorecidas con un estatuto jurídico privilegiado, lo cierto es que en determinadas zonas este fenómeno monetario pudo afectar y, además de manera muy notable, a otro tipo de centros. Precisamente, en la zona occidental y central del Imperio, esta difusión de centros emisores en relación a urbes no privilegiadas se constata solo en la provincia del África Proconsular. En el resto son muchísimo más numerosas las ciudades-cecas con condición colonial y/o municipal, estando casi ausentes los talleres asociados a otro tipo de poblaciones. Así ocurre también en la propia provincia Mauretania; territorio en el que curiosamente fue escasamente divulgada la fundación o promoción de estos centros con status privilegiado. No obstante, en las provincias orientales sí que se constata la propagación de cecas en ciudades con condición diversa, especialmente en regiones en las que las colonias y municipios fueron poco numerosos.

Mucho se ha discutido acerca de la necesidad o no de un permiso imperial para que una ciudad pudiera emitir moneda provincial. La

12. Lamentablemente en la actualidad existen numerosas dificultades para precisar el status jurídico de las ciudades asociadas a determinados centros emisiones, especialmente por lo que respecta a los momentos iniciales de amonedación provincial. En este sentido, cabe recordar que al desconocimiento acerca de la propia condición precisa de algunas de estas ciudades, se puede sumar también la circunstancia de que ignoremos también datos monetarios tan importantes como son el propio centro emisor exacto donde se fabricó la pieza o la cronología precisa de su puesta en circulación.

13. Ripollès, P. P.: "Ancient Iberian Coinage", Documentos Digitales de Arqueología, 2, 2013, p. 46. 
controversia del tema ha sido bien detallada en diversos trabajos ${ }^{14}$, destacando su probable conexión con algunas fuentes literarias y epigráficas y, más específicamente con la leyenda PERMISsv o alguna de sus diversas variantes. Estos epígrafes se encuentran presentes en algunas escasas monedas, acuñadas tan solo en determinadas provincias, como fue en la propia África Proconsular (en concreto en piezas batidas en Paterna ${ }^{15}$, Cercina $^{16}$ y Thaena $^{17}$ ). Sin entrar en mayores precisiones acerca del tema, es preciso mencionar que la escasez de testimonios que documenten este fenómeno no permite proporcionar una respuesta realmente concluyente ante este interrogante. Por este motivo, si bien no puede descartarse que este tipo de controles pudiera existir, en nuestra opinión, resulta mucho más relevante destacar los propios intereses de las ciudades por solicitar dichos permisos, evidenciándose el interés que aquellas tuvieron por la fabricación monetaria.

\begin{tabular}{|c|c|c|c|c|c|c|}
\hline $\begin{array}{l}\text { CENTRO } \\
\text { EMISOR }\end{array}$ & $\begin{array}{l}\text { CONDICIÓN } \\
\text { JURÍDICA }\end{array}$ & $\begin{array}{c}\text { EMISIONES } \\
\text { AUGUSTEAS }\end{array}$ & $\begin{array}{l}\text { EMISIONES } \\
\text { TIBERIANAS }\end{array}$ & $\begin{array}{c}\text { EMISIONES } \\
\text { AUGUS- } \\
\text { TEAS O } \\
\text { TIBERIANAS }\end{array}$ & $\begin{array}{c}\text { EMISIONES CON } \\
\text { CRONOLOGÍA } \\
\text { INCIERTA }\end{array}$ & TOTAL \\
\hline $\begin{array}{c}\text { Cirtal } \\
\text { Constantine }\end{array}$ & Colonia & 5 & & & & 5 \\
\hline Sicca & Colonia & 3 & & & & 3 \\
\hline $\begin{array}{l}\text { Hippo } \\
\text { Regius }\end{array}$ & Municipium & 2 & 3 & 3 & & 8 \\
\hline Utica & Municipium & & 28 & & & 28 \\
\hline Carthago & Colonia & 9 & 4 & & & 13 \\
\hline Paterna & Colonia & 5 & 9 & & & 14 \\
\hline $\begin{array}{l}\text { Hadrume- } \\
\text { tum }\end{array}$ & Ciudad libre & 14 & & & & 14 \\
\hline $\begin{array}{l}\text { Leptis } \\
\text { Minus }\end{array}$ & Ciudad libre & 9 & & & & 9 \\
\hline
\end{tabular}

14. Burnett, A.: 1993, pp. 151-153; Burnett, A., Amandry, M. \& Ripollès P. P.: 2006, pp. 12-3; RIPOLlès P. P.: Las acuñaciones provinciales de Hispania. Madrid, 2010, pp. 337 y 362-364.

15. RPC I, 762-770.

16. $R P C \mathrm{I}, 802$.

17. $R P C \mathrm{I}, 810$. 
HELENA GOZALBES GARCÍA

LA PRODUCCIÓN DE MONEDA PROVINCIAL JULIO-CLAUDIA

EN EL AFRICA PROCONSULARIS

\begin{tabular}{|c|c|c|c|c|c|c|}
\hline $\begin{array}{l}\text { CENTRO } \\
\text { EMISOR }\end{array}$ & $\begin{array}{l}\text { CONDICIÓN } \\
\text { JURÍDICA }\end{array}$ & $\begin{array}{c}\text { EMISIONES } \\
\text { AUGUSTEAS }\end{array}$ & $\begin{array}{l}\text { EMISIONES } \\
\text { TIBERIANAS }\end{array}$ & $\begin{array}{c}\text { EMISIONES } \\
\text { AUGUS- } \\
\text { TEAS O } \\
\text { TIBERIANAS }\end{array}$ & $\begin{array}{c}\text { EMISIONES CON } \\
\text { CRONOLOGÍA } \\
\text { INCIERTA }\end{array}$ & TOTAL \\
\hline Thapsus & ¿Ciudad libre? & 3 & 3 & & & 6 \\
\hline Achulla & Ciudad libre & 4 & & & & 4 \\
\hline Cercina & Ciudad libre & 2 & & & & 2 \\
\hline Thaena & Ciudad libre & 9 & & 1 & & 10 \\
\hline Sabratha & Ciudad libre & 5 & 6 & 4 & & 15 \\
\hline Oea & Ciudad libre & 6 & 6 & 2 & & 14 \\
\hline $\begin{array}{l}\text { Lepcis } \\
\text { Magna }\end{array}$ & Ciudad libre & 8 & 5 & & & 13 \\
\hline $\begin{array}{l}\text { Descono- } \\
\text { cida }^{18}\end{array}$ & - & & & & 1 & 1 \\
\hline Total & & 84 & 64 & 10 & 1 & 159 \\
\hline
\end{tabular}

Figura 1. Periodos representados en el monetario provincial del África Proconsular, según ceca y número de series emitidas.

Como se ha indicado, la producción de monedas cívicas afectó a todas las provincias del Imperio. No obstante, lo cierto es que generalmente, y a excepción de alguna serie particular, las cantidades de piezas emitidas por las cecas locales fueron mucho menos voluminosas que las producidas por los talleres controlados por la propia capital ${ }^{19}$. Además, las emisiones no se desarrollaron en ningún momento en intervalos totalmente regulares, ni se pusieron en circulación todas ellas de manera simultánea. La mayor parte de las cecas, de hecho, tuvieron una escala de producción muy escasa ${ }^{20}$. Así puede suponerse que ocurrió en la propia África Proconsular, donde las emisiones de cada centro no fueron, a excepción de algún caso, muy numerosas. La mayor parte de estos talleres se incorporaron a la producción de manera progresiva, muy especialmente a partir del principado de Augusto, que fue precisamente el momento en el que más oficinas

18. RPC-S.852A.

19. BURNETT, A.: 2011, p. 2.

20. BuRnetT, A.: 1993, p. 148. 
estuvieron en actividad ${ }^{21}$. Así ocurrió también en la propia provincia del África Proconsular.

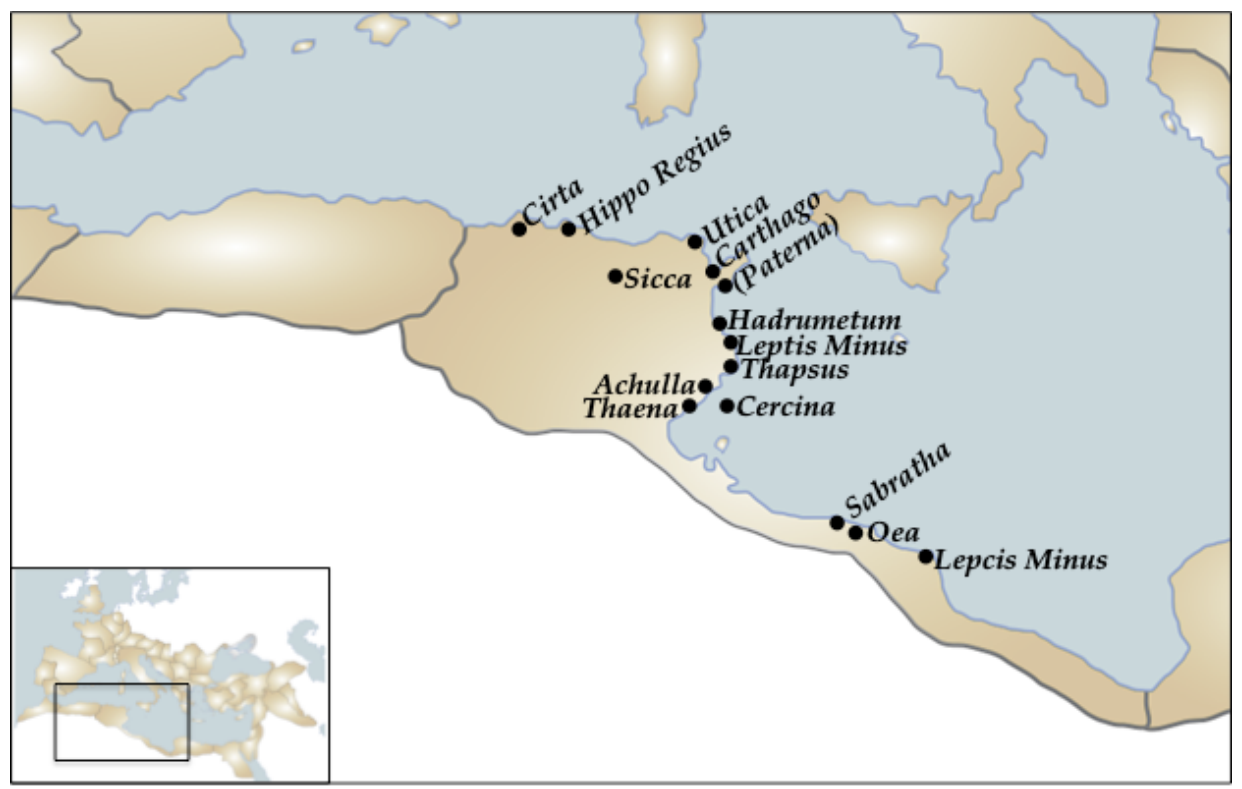

Figura 2. Dispersión de los talleres provinciales del África Proconsular.

En este contexto de producción monetaria irregular, resulta evidente que debieron de existir sustanciales diferencias en las producciones monetarias locales de las diversas provincias del Imperio de modo que el fenómeno se desarrolló de manera particularmente desigual en todas ellas. Frente a las numerosas cecas que acuñaron en la parte oriental del Imperio, donde además la producción fue especialmente constante y variada en cuanto a denominaciones y no cesó de manera general hasta mediados del gobierno de Diocleciano (297 d. C.), en la zona occidental y central, que es en la que se encuadra nuestro estudio, el número de centros emisores fue mucho menor y, además, la fabricación oficial se paralizó de modo totalmente general durante el imperio de Claudio (41-54 d. C.) ${ }^{22}$. Es más,

21. Burnett, A., Amandry, M. \& Ripollès, P. P.: 2006, p. 17.

22. Según se ha concluido, posiblemente las últimas piezas batidas por talleres provinciales no orientales fueron puestas en circulación por la ciudad de Ebusus en la provincia Citerior Tarraconensis (RPC I, 482 y 482 A). Precisamente, si aceptamos esta cronología sería esta oficina la única que en la zona occidental y central del Imperio acuñó moneda en esta época, pues el resto finalizó su actividad años antes. En este sentido, cabe 
por lo que respecta a este segundo grupo de cecas, lo cierto es que algunos factores difíciles de precisar ocasionaron que ya durante el gobierno de Tiberio los talleres y las producciones fueran disminuyendo progresivamente. Entre ellos, los africanos cuya actividad se interrumpió durante este periodo de gobierno, produciéndose entonces también la insalvable sustitución de estas monedas locales por las metropolitanas ${ }^{23}$. Así ocurrió también en la mayor parte de territorios occidentales y centrales, donde el final del breve periodo de mando de Calígula supuso la definitiva clausura de casi la totalidad de cecas, restringidas, pocos años antes, a talleres muy poco numerosos y escasamente voluminosos diseminados únicamente por la provincia Citerior Tarraconensis, en el territorio hispano.

Por lo que respecta al número de talleres provinciales, en el África Proconsular fue durante el principado de Augusto el momento en el que estuvieron en actividad un mayor número de ellos, siendo además los instantes de mayor producción. En estos años, que coincidieron también con los instantes de apertura de casi la totalidad de los centros ${ }^{24}$, iniciaron su actividad 14 de las 15 oficinas conocidas. Entre ellas, Cirta ${ }^{25}$, Sicca $^{26}$, Hadrumetum $^{27}$, Leptis Minus ${ }^{28}$, Achulla $^{29}$, Cercina $^{30}$ y Thaena ${ }^{31}$, las cuales debieron de interrumpir su actividad monetaria con anterioridad

mencionar que algunos de los ejemplares disponibles de estas emisiones posiblemente tardías proceden de hallazgos arqueológicos, evidenciándose, de este modo, la autenticidad de los mismos. No obstante, la particular circunstancia de que estas monedas sean anepígrafas dificulta enormemente su atribución cronológica, que según algunos autores es bastante dudosa (GIARD, J. B: "Pouvoir central et libertés locales. Le monnayage en bronze de Claude avant 50 après J.-C.", Revue Numismatique, XII, 1970, p. 42; Sutherland, C. H. V.: Romans in Spain. London, 1939, p. 245), pero que otros aceptan y defienden (CAMPO, M.: "Las monedas de Claudio de la ceca de Ebusus", Nvmisma, 1976, pp. 159-163; Id.: Las monedas de Ebusus. Barcelona,1976, pp. 48-49; RIPOLlÈs, P. P.: 2010, pp. 291-292).

23. Burnett, A.: 2001-2002.

24. Pese a que existen más de una decena de monedas con cronología incierta, lo cierto es que la circunstancia de que la mayor parte de ellas puedan agruparse en el imperio de Augusto o en el de Tiberio apoyan la interpretación de que la producción de moneda provincial se inició en el África Proconsular en los años augusteos. La única salvedad, en este sentido, que podría plantear alguna reserva a esta hipótesis está constituida por la insólita emisión publicada como posiblemente africana cuya cronología y ceca aún se desconocen (RPC-S-852A) y que, pese a todo, consideramos que dudosamente puede considerarse como una acuñación pre-imperial.

25. $R P C$ I, 701-705.

26. $R P C \mathrm{I}, 706-708$.

27. $R P C \mathrm{I}, 771-783$; $R P C-\mathrm{S} 2-\mathrm{I}-774 \mathrm{~A}$.

28. $R P C$ I, 784-791; $R P C-\mathrm{S} 3-\mathrm{I}-790 \mathrm{~A}$.

29. $R P C \mathrm{I}, 798-801$.

30. $R P C \mathrm{I}, 802 ; R P C-\mathrm{S} 4-802 \mathrm{~A}$.

31. RPC I, 803-810, RPC-S2-805A; RPC-S2-806A. 
a la finalización de este periodo e, Hippo Regius ${ }^{32}$, Carthago ${ }^{33}$, Paterna ${ }^{34}$, Thapsus $^{35}$, Sabratha ${ }^{36}$, Oea ${ }^{37}$ y Lepcis Magna ${ }^{38}$, que, en cambio, mantuvieron su producción durante los años del imperio de Tiberio. En aquellos momentos constatamos la apertura de un nuevo taller, el de Utica ${ }^{39}$, cuya producción, aunque menos dilatada en el tiempo que la verificada para el resto, fue la más voluminosa.

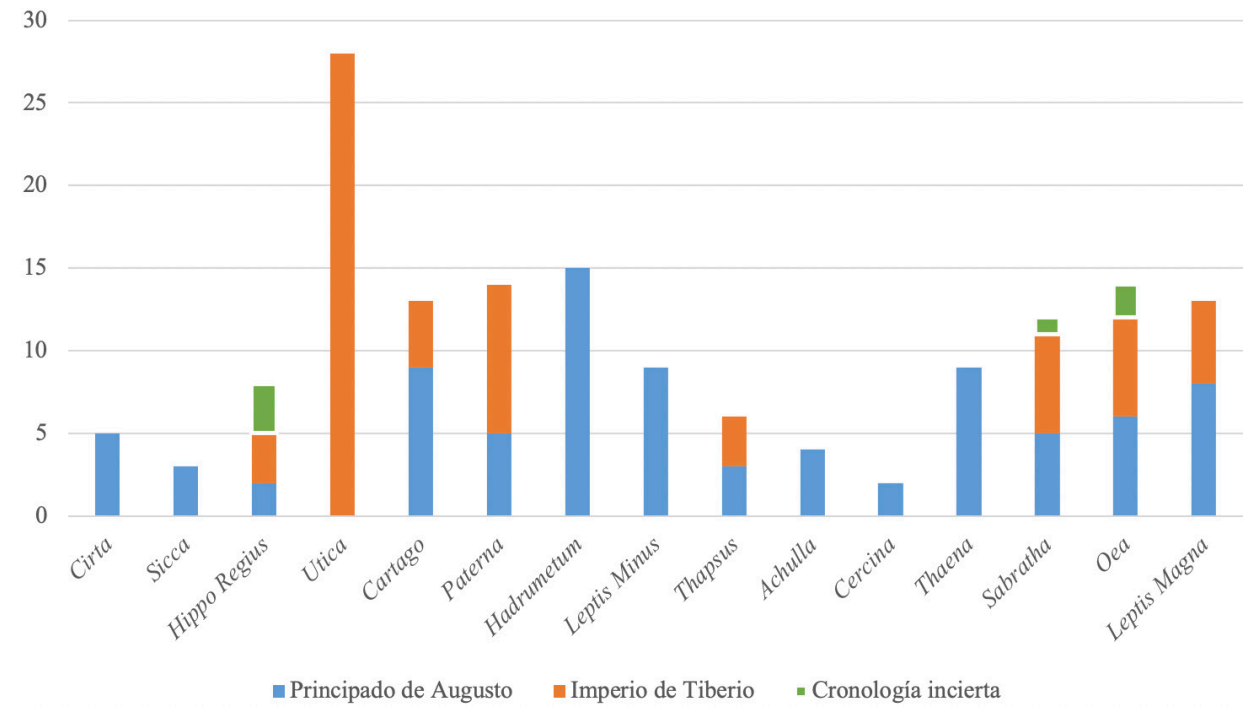

Figura 3. Estimación del número de ejemplares emitidos por cada una de las cecas provinciales del África Proconsular, según cronología y número de series distintas emitidas.

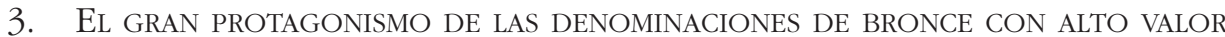
en las emisiones Cívicas del África Proconsular

La producción de moneda provincial romana se circunscribió en la mayor parte de las provincias del Imperio a dos tipos de especies

32. $R P C$ I, 709-716.

33. $R P C$ I, 745-757.

34. $R P C$ I, 758-770; RPC-S4-759A.

35. $R P C$ I, $792-797$.

36. $R P C \mathrm{I}, 811-825$.

37. $R P C \mathrm{I}, 826-839$.

38. RPC I, 840-852.

39. $R P C$ I, 721-744; $R P C$-S2-I.721A; $R P C-S .722 \mathrm{~A} ; R P C$-S2-I.723A; $R P C-$ S.724A. 
monetarias $^{40}$. De un lado, las denominaciones que conservaron los aspectos fundamentales del régimen tradicional pre-provincial, caracterizado por la escasa homologación de sus pesos y medidas. Estos, por tanto, podían variar considerablemente en función de la región e, incluso, de la ciudad en la que se desarrollasen ${ }^{41}$, de modo que lograron sobrevivir sin adecuarse al sistema de la capital en amplias zonas, especialmente en las provincias orientales. No obstante, en el África Proconsular se encontraron casi totalmente ausentes. Con todo, de las 160 distintas emisiones puestas en circulación por los centros de esta provincia, tan solo se ha constatado una serie con un peso que pudo no haberse adecuado al oficial romano. Nos referimos, en este caso, a una moneda fabricada en plata por Lepcis Magna $^{42}$, seguramente bajo el Principado ${ }^{43}$, cuyo peso era menor al del denario romano. Según se intuye, esta variación pudo deberse a que tal vez correspondiera a un estándar local ${ }^{44}$ de previa aprobación; si bien los datos de pesos y medidas constatados para el monetario anterior no evidencian una clara relación entre esta emisión provincial y las fabricadas en años $\operatorname{previos}^{45}$.

40. Burnett, A., Amandry, M. \& Ripollès, P. P.: 2006, pp. 9-13 y 26-30.

41. Este hecho plantea la posibilidad de que en algunos momentos se desarrollasen verdaderas escalas monetarias independientes con una capacidad de influencia particular en determinadas provincias (BURNETT, A.: 1993, p. 146). Estas escalas monetarias pudieron ser incluso incompatibles con el sistema metropolitano, desarrollado, en todo caso, generalmente en términos no exclusivamente cerrados, esto es, admitiendo en algunas ocasiones el uso de monedas metropolitanas en algunos mercados locales. Y es que, tal y como recuerda A. Burnett, aunque el sistema monetario republicano romano hubo de desarrollarse en términos generalmente cerrados, son muchos los casos de hallazgos de conjuntos monetarios en los que ya desde época tardo-republicana convivían piezas locales con valores particulares junto a monedas de fábrica metropolitana, evidenciándose el uso compartido de las mismas (BurnetT, A.: 1987, pp. 86-87).

42. $R P C \mathrm{I}, 847$.

43. Burnett, A., Amandry, M. \& Ripollès, P. P.: 2006, pp. 208-209; Grant, M.: 1946, p. 340; Nicolau Kormikiari, M. C.: "Norte da África na antiguidade: os reis berberes númidas e suas iconografías monetarias", Revista do Museo de Arqueologia e Etnologia São Paulo, 17, 2007, p. 259.

44. Burnett A., Amandry, M. \& Ripollès, P. P.: 2006, p. 182

45. Los cospeles utilizados en la fabricación de monetario en plata se caracterizaban por un ajuste bastante más preciso que el de los utilizados para la producción de piezas en bronce, de modo que las variaciones deberían haber sido bastante poco perceptibles. 
HELENA GOZALBES GARCÍA

LA PRODUCCIÓN DE MONEDA PROVINCIAL JULIO-CLAUDIA

EN EL AFRICA PROCONSULARIS

\begin{tabular}{|c|c|c|c|c|c|c|c|}
\hline CENTRO EMISOR & $\begin{array}{c}\text { SESTERCIOS Y/ DOBLES } \\
\text { DUPONDIOS }\end{array}$ & DuPONDIOS & AsES & SEMises & TRIENS & CUADRANTES & TOTAL \\
\hline $\begin{array}{c}\text { Cirtal } \\
\text { Constantine }\end{array}$ & 1 & 1 & 1 & 1 & & 1 & 5 \\
\hline Sicca & & 2 & 1 & & & & 3 \\
\hline Hippo Regius & 2 & 1 & 2 & 2 & & 1 & 8 \\
\hline Utica & & 14 & 10 & 2 & & 2 & 28 \\
\hline Carthago & & & 6 & 4 & & 3 & 13 \\
\hline Paterna & 3 & 7 & 4 & & & & 14 \\
\hline Hadrumetum & 4 & 4 & 1 & 5 & & & 14 \\
\hline Leptis Minus & 2 & 2 & 5 & & & & 9 \\
\hline Thapsus & 1 & 1 & 4 & & & & 6 \\
\hline Achulla & 1 & 2 & 1 & & & & 4 \\
\hline Cercina & 2 & & & & & & 2 \\
\hline Thaena & 2 & 7 & 1 & & & & 10 \\
\hline Sabratha & & 4 & 6 & 3 & 2 & & 15 \\
\hline Oea & 1 & 3 & 4 & 3 & & 3 & 14 \\
\hline Lepcis Magna & 2 & 2 & 2 & 5 & & 1 & 12 \\
\hline Total & 21 & 50 & 48 & 25 & 2 & 11 & 157 \\
\hline
\end{tabular}

Figura 4. Valores representados en el monetario provincial del África Proconsular, según ceca y número de series distintas emitidas.

De otro lado, se encuentran los valores de nueva implantación, cuya producción, a juzgar por los datos de peso de las piezas, debió divulgarse en la mayor parte de provincias del Imperio, siendo las únicas especies monetarias en algunas zonas, especialmente en las regiones más occidentales. Cabe, en todo caso, recordar que lamentablemente en la actualidad se desconocen los nombres precisos que pudieron haber tenido estas emisiones provinciales, en caso de que estas no hubieran recibido aquellos incorporados en el sistema monetario metropolitano, al que, de hecho, tal y como evidencian los propios pesos de los ejemplares podrían haberse 
asimilado ${ }^{46}$. En este caso, podría deducirse que seguirían los términos especificados en la reforma monetaria emprendida por Augusto en el año 23 a. C. ${ }^{47}$, a la que, en todo caso, las emisiones se adecuaron de manera desigual y progresiva. Por este motivo, tal y como advierten autores como P. P. Ripollès ${ }^{48}$ y M. Amandry ${ }^{49}$, dado que los cospeles utilizados en la fabricación de la mayor parte de las emisiones en bronce a menudo carecían de una abundante precisión, aquellas, aun perteneciendo al mismo sistema monetario, pudieron presentar unas variaciones de peso bastante considerables $^{50}$. Así, por ejemplo, por lo que respecta al monetario de fábrica africana, a lo largo del Principado las unidades bases pudieron superar los 10 gramos en centros meridionales como $O e a^{51}$ o en Sabratha ${ }^{52}$, mientras que en cambio en otras cecas como Carthago $^{53}$ o Thapsus $^{54}$ se acuñaron series de ases que no llegaron a tener ni 6 gramos. Es más, durante el imperio de Tiberio las variaciones de peso aumentaron considerablemente, de modo que incluso en Sabratha se pusieron en circulación dos emisiones

46. Cabe puntualizar que al desconocer las denominaciones precisas que pudieron haber recibido las emisiones provinciales, la mayor parte de investigadores emplean los nombres de las series metropolitanas que sí conocemos. Por estas razones, para nuestro trabajo, también hemos asumido estas denominaciones tomando la horquilla de pesos y medidas recogida en el volumen del Roman Provincial Coinage (BurnetT A., AMAndry, M. \& Ripollès, P. P.: 2006, pp. 186-209)

47. Esta reforma monetaria no fue totalmente inaudita, sino que, por el contrario, tal y como detallan M. Amandry y J.-N. Barrandon, supuso la culminación de un largo proceso de innovaciones monetarias que comenzaron un siglo antes de la puesta en circulación de las propias emisiones provinciales (AMANDRY, M. et BARRANDON, J.-N.: "La genèse de la réforme monétaire augustéenne", en García-Bellido, M. P., Mostalac, A. y Jiménez, A. (eds.): Del imperium de Pompeyo a la auctoritas de Augusto. Homenaje a Michael Grant. Madrid, 2008, pp. 209-233).

48. Ripollès, P. P.: 2010, pp. 19-20.

49. Amandry, M.: "Tingi (32 av. J.-C.- 29 après) ", en Huvelin, H., Christol, M. et Gautier, G. (eds.): Mélanges de numismatique: offerts à Pierre Bastien à l'occasion de son 75 e anniversaire. Wetteren, 1987, p. 13.

50. En este sentido, podría ser de interés recordar que, en algunos casos, las diferencias de peso podrían explicarse teniendo en consideración que los sestercios fabricados por algunas cecas se batieron en piezas de bronce y en otros centros sobre ejemplares producidos en oricalco. Esta idea, sugerida hace algunas décadas por M. Amandry en relación a diversas series emitidas por algunas ciudades de la Mauritania Tingitana (AMANDRY, M.: 1987, p. 13), podría resultar bastante verosímil también en lo concerniente a algunas producciones del África Proconsular.

51. $R P C$ I, 827.

52. RPC I, 811.

53. $R P C \mathrm{I}, 747$.

54. $R P C$ I, 792. 
HELENA GOZALBES GARCÍA

LA PRODUCCIÓN DE MONEDA PROVINCIAL JULIO-CLAUDIA

EN EL AFRICA PROCONSULARIS

tan dispares como la serie de ases que llegó a superar los 15 gramos $^{55}$ y la que no alcanzó ni la mitad de dicho peso ${ }^{56}$.En cualquier caso, fuesen valores de tradición pre-provincial o denominaciones de nueva implantación, todos ellos se encontraron fabricados en dos metales principalmente ${ }^{57}$. Por una parte, se encontraban las piezas elaboradas en plata, que fueron puestas en circulación tan solo esporádicamente y únicamente por determinadas cecas del Imperio. Además, esta producción de numisma en metal precioso se desarrolló habitualmente en centros controlados por monarcas locales clientelares del Imperio y/o en cecas que tenían una gran tradición en la fabricación de piezas en esta materia. No obstante, en ocasiones pudo convertirse en un fenómeno que afectó a las mismas de una manera particularmente intensa. Con todo, la moneda en plata se producía generalmente para que circulase en toda una región o incluso provincia $^{58}$, pues además con bastante frecuencia se relacionaba directamente con los requerimientos de las instituciones del Estado central asentadas en aquel territorio. Este fenómeno se desarrollaba especialmente cuando a los mencionados organismos les resultaba, por diversas razones, más práctico abastecerse de monetario de acuñación provincial que de aquel producido por los talleres imperiales. Por estos motivos, aunque las necesidades locales de moneda en plata a nivel general pudieron ser más limitadas que las que existieron con respecto a piezas de menor valor, lo cierto es que, dado que las cecas que las fabricaban eran muy poco numerosas, las demandas que recibían pudieron tener ocasionalmente un cierto alcance.
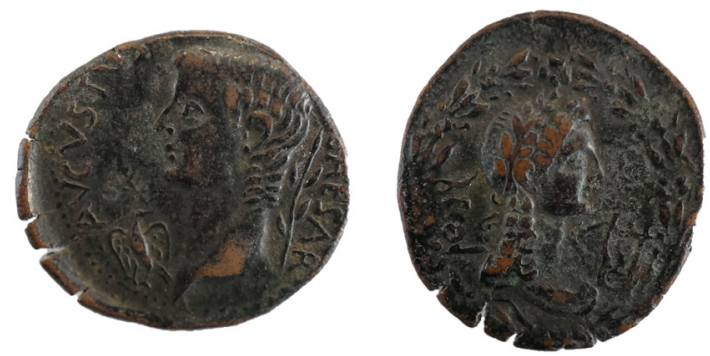

Figura 5. As acuñado en Oea bajo el imperio de Tiberio (RPC I, 832) (Ashmoleum Museum collection).

55. $R P C \mathrm{I}, 817$.

56. $R P C \mathrm{I}, 818$.

57. Las producciones monetarias en oro fueron muy excepcionales y, de hecho, en la zona y época objetos de estudio los ejemplares fabricados en este metal están completamente ausentes.

58. Burnett, A.: 1993, p. 145. 
Por otra parte, se encontraban las monedas cívicas fabricadas en bronce, oricalco y/o cobre. Estas, además de acuñarse en todas las provincias, fueron mucho más numerosas y prolíferas que las anteriormente comentadas. Fue así, de hecho, como ocurrió en la propia África Proconsular, donde tan solo se acuñó una ocasional emisión de moneda en plata. Nos referimos a la pieza puesta en circulación por Lepcis Magna y comentada en anteriores párrafos. En todo caso, por lo que respecta a las especies monetarias más extendidas en la provincia, esto es las que pudieron fabricarse siguiendo el sistema metropolitano de moneda en bronce, en el África Proconsular se constata una producción muy variada en cuanto a posibles denominaciones.

Determinadas cecas pusieron en circulación algunas series con un valor divisorio. De entre ellas, hubo un taller que incorporó a su producción monetaria una fabricación de divisores, a juzgar por los datos de los que se dispone, bastante homogénea. Nos referimos, en efecto, a Hadrumetum; centro que puso en circulación cinco series de semises ${ }^{59}$. El resto de cecas que acuñaron moneda divisoria tuvieron una amonedacción mucho más variada. Cirta/Constantine acuñó 1 serie de semises ${ }^{60}$ y otra de cuadrantes $^{61}$, Hippo Regius fabricó 2 emisiones de semises ${ }^{62}$ y otra de cuadrantes ${ }^{63}$, Utica puso en circulación 2 grupos de ejemplares de semises ${ }^{64}$ y otros 2 de cuadrantes ${ }^{65}$, Carthago, por su parte, batió cuatro series de semises ${ }^{66}$ y otras 3 de cuadrantes ${ }^{67}$, Oea, en cambio, puso en circulación 3 emisiones de semises ${ }^{68}$ y otras 3 de cuadrantes ${ }^{69} \mathrm{y}$, finalmente, Lepcis Magna, produjo 5 series de semises ${ }^{70}$ y 1 de cuadrantes ${ }^{71}$. Junto a ellas, Sabratha incorporó un particular valor monetario divisorio, pues además de emitir 3 series de semises $^{72}$, fabricó dos de posibles triens ${ }^{73}$.Hubo, sin embargo, numerosas ciudades que no acuñaron denominaciones divisorias. De un lado, Sicca

59. $R P C \mathrm{I}, 774,774$ A y $781-783$.

60. $R P C \mathrm{I}, 704$.

61. $R P C \mathrm{I}, 705$.

62. $R P C$ I, 714-715.

63. $R P C \mathrm{I}, 716$.

64. $R P C$ I, 727-728.

65. $R P C$ I, 729-730.

66. $R P C$ I, $749-751$ y 756 .

67. $R P C \mathrm{I}, 752-753$ y 757.

68. $R P C$ I, 830 y $836-837$.

69. $R P C$ I, 831 y $838-839$.

70. $R P C \mathrm{I}, 840,844-846$ y 852.

71. RPC I, 841.

72. $R P C \mathrm{I}, 821-823$.

73. $R P C \mathrm{I}, 824-825$. 
y Paterna, en la región septentrional y Leptis Minus, Thapsus, Achulla, Cercina y Thaena, en la zona central. Además, si se contemplan los números estimados de la producción africana general por denominaciones, se puede apreciar una reducción gradual de los valores divisorios. De hecho, durante el imperio de Tiberio la emisión de estas especies monetarias fue casi anecdótica, hasta tal punto que en aquellos momentos no se constata ninguna fabricación de cuadrantes. Esta tendencia, como recuerda A. Arévalo en su estudio sobre las emisiones hispanas, puede ponerse en relación con lo que sucedió en los talleres metropolitanos y el resto de cecas provinciales ${ }^{74}$.Y es que si hay un hecho verdaderamente asombroso de la producción monetaria por valores del África Proconsular es el gran protagonismo de series asociadas a valores múltiplos, muy especialmente del dupondio. Este fenómeno no se constata en otros territorios emisores de moneda provincial romana y plantea un escenario bastante particular. Según se observa, a diferencia de lo constatado para la mayor parte de provincias productoras de monetario provincial, las monedas africanas que recogieron como especie el dupondio fueron puestas en circulación por casi la totalidad de cecas, a excepción de dos. De un lado, Carthago, que por otra parte no emitió ninguna denominación de mayor valor que el as y, de otro Cercina, que por su parte sí acuñó dos series de sestercios ${ }^{75}$. Al margen de estos excepcionales casos, hubo cecas en las que el dupondio tuvo un gran protagonismo, especialmente en la zona norte. Así ocurrió en $\operatorname{Sicca}^{76}$, con 2 de las 3 amonedaciones batidas por la ciudad, $\mathrm{Utica}^{77}$, con 14 de las 28 monedas que acuñó, Paterna ${ }^{78}$, con 7 de las 14 emisiones que puso en circulación o Thaena ${ }^{79}$, con 7 de las 10 series que produjo. Curiosamente, los talleres en cuyas producciones no despuntó con tanta claridad la fabricación de dupondios fueron aquellos en los que, por lo general, se incluyó también la acuñación, en algunos casos destacada, de sestercios que completaban la gran masa de denominaciones de alto valor emitidas. De este modo se observa en Cirta, la cual puso en circulación 5 series, de las cuales 1 era de sestercios ${ }^{80}$ y otra de dupondios ${ }^{81}$, Hadrumetum, que emitió 14 series, de entre las que 4 eran de sestercios/doble

74. Arévalo, A.: "La moneda provincial romana de Hispania en el Museo de Cádiz", en La colección de moneda del Museo de Cádiz. Sevilla, 2005, p. 62.

75. $R P C \mathrm{I}, 802 ; R P C-\mathrm{S} 4-802 \mathrm{~A}$.

76. $R P C \mathrm{I}, 706-707$.

77. $R P C$ I, 731-744.

78. $R P C$ I, 759-761, 763, 766 y 766; $R P C-S 4-759 \mathrm{~A}$

79. $R P C \mathrm{I}, 803,805-807$ y $810 ; R P C-\mathrm{S} 2-805 \mathrm{~A} ; R P C-\mathrm{S} 2-806 \mathrm{~A}$.

80. RPC I, 701

81. $R P C$ I, 702. 
dupondios $^{82}$ y otras 4 de dupondios ${ }^{83}$, al igual que ocurre en Leptis Minus, de cuyas 9 emisiones 2 eran de sestercios ${ }^{84}$ y otras 2 de dupondios ${ }^{85} \mathrm{y}$, finalmente, Achulla que, por su parte, emitió 4 emisiones, entre las que hubo 1 de sestercios ${ }^{86}$ y 2 de dupondios ${ }^{87}$.

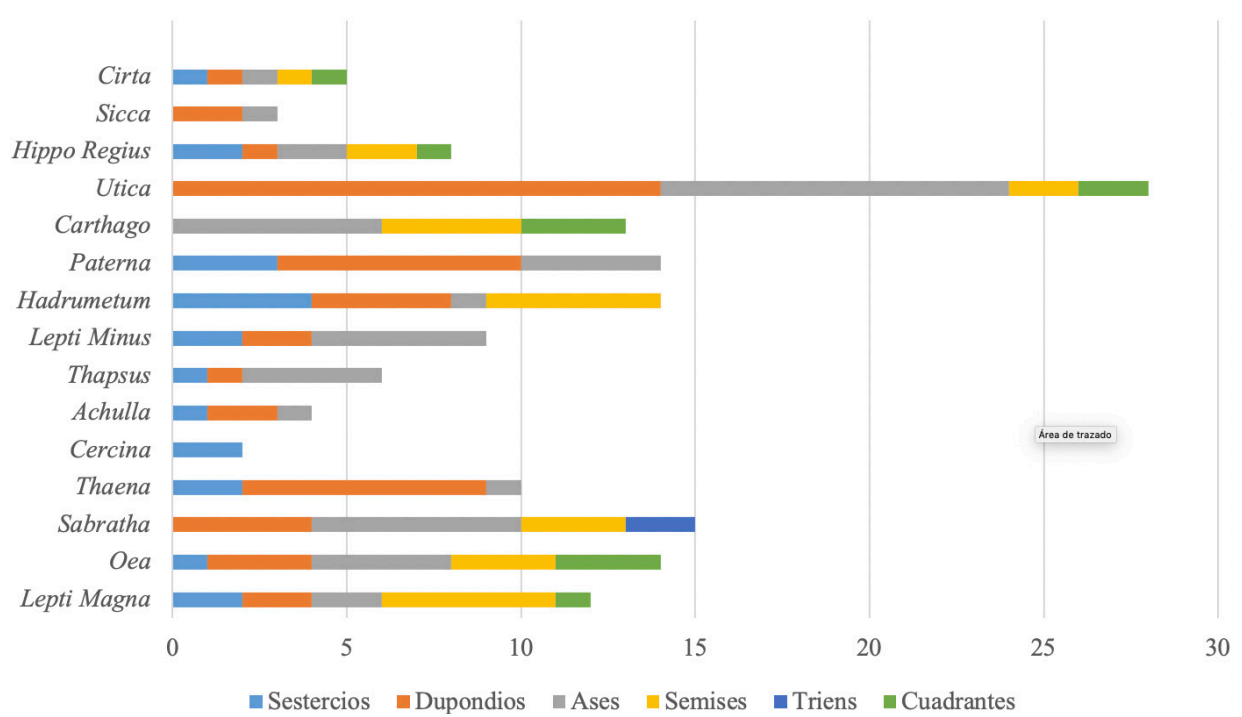

Figura 6. Estimación del número de ejemplares emitidos según valores por cada una de las cecas del África Proconsular, según centro y número de series distintas emitidas.

Las series monetarias en bronce con altos valores, como se observa, eran las que con mayor frecuencia se emitieron, suponiendo el $45 \%$ sobre el total. Parece, por tanto, posible afirmar que la fabricación de series de alto valor, ya se refiriesen a dupondii o a sestertii, tuvo un excepcional desarrollo en las cecas del África Proconsular. Además, este protagonismo se constata generalmente en los centros con mayor producción de emisiones. Ahora bien, aunque en estas líneas no se va a detallar con precisiones acerca de este asunto, pues sería para ello necesario incluir un completo estudio de cuños que no es el objetivo del presente trabajo, resulta necesario

82. $R P C \mathrm{I}, 771,775,777$ y 779 .

83. $R P C \mathrm{I}, 772,776,778$ y 780 .

84. $R P C$ I, 784 y 788.

85. RPC I, 785 y 789.

86. $R P C \mathrm{I}, 799$.

87. RPC I, 798 y 800. 
advertir, aunque sea someramente, que el número de ejemplares batidos en una emisión monetaria de alto valor podía ${ }^{88}$ ser diferente al número de piezas acuñadas en una serie que recogiera una riqueza menor ${ }^{89}$. Por este motivo, en el caso africano, cabe señalar que el volumen de producción por denominaciones muy posiblemente no se correspondiera al volumen de acuñaciones por especie monetaria, pudiendo ser más numerosas las piezas de menor valor que las que representaban una riqueza mayor ${ }^{90}$. No obstante, pese a que no se debe perder de vista este hecho, lo cierto es que el predominio de especies monetarias de alto valor en las distintas emisiones provinciales del África Proconsular, en general, y en las de las cecas más productoras, en particular, puede plantear la posibilidad de que las demandas de este tipo de monetario fueran especialmente significativas; por más que aceptemos que ciertamente el volumen de ejemplares supusiese un porcentaje bastante menor. La necesidad de batir distintas series y que lo hiciesen los centros a priori más dinámicos, es decir, los que según los datos de emisión fabricaban un mayor numerario, bien podría evidenciar el auge que estaban experimentando en la provincia la producción de sestercios y dupondios, sobre todo si consideramos lo que ocurre en otros territorios.

88. Es cierto que, tal y como vienen insistiendo algunos autores (ButREy, T. V.: "Calculating ancient coin production: fact and fantasies", Numismatic Chronicle, 153, 1993; Id.: "Calculating ancient coin production II: why it cannot be done", Numismatic Chronicle, 154, 1994; GARCía VARGAS, E.: "Aspectos económicos de la moneda romana imperial", en La moneda de l'Imperi romà. VIII Curs d'Història monetària d'Hispània (25 i 26 de noviembre de 2004. Barcelona, 2004); Howgego, C.: "The supply and use of money in the Roman World 200 B. C. to A. D. 300", Journal of Roman Studies, 82, 1992; SAVIO, A.: "La numismatica e i problemi quantitativi: in torno al calcolo del volume delle emisioni", Rivista italiana di Numismatica, 98, 1997), los estudios sobre volumen de producción monetaria presentan series limitaciones metodológicas. Además, en nuestra opinión, podría ser altamente especulativo suponer que los volúmenes de emisión de la moneda antigua fueron similares en todas las épocas y territorios, de modo que para poder incluir alguna conclusión más o menos ilustrativa en este sentido sería necesario incluir un estudio lo suficientemente completo sobre el número de ejemplares africanos que se conservan en la actualidad.

89. Howgego, C.: La storia antica attraverso le monete. Roma, 2002, p. 36.

90. Con la cautela que este asunto precisa, dada la ausencia de un estudio que estime el posible número de distintos cuños utilizados para la fabricación de las diversas piezas africanas, nosotros somos de la opinión de que los troqueles utilizados en las series de mayor tamaño, como eran por ejemplo las de sestercios y dupondios, generalmente debían producir un menor número de ejemplares que los usados en emisiones de menor tamaño, como los ases y sus unidades fraccionarias. Con todo, tal y como advierte $\mathrm{T}$. Hurtado Mullor, la utilización de cospeles de grandes dimensiones podía ocasionar la aparición de grietas en los mismos, favoreciendo el desgaste de los propios cuños (HuRTADO Mullor, T.: Las emisiones monetarias de la Colonia Victrix Iulia Lepida-Celsa. Valencia, 2013, p. 337). 


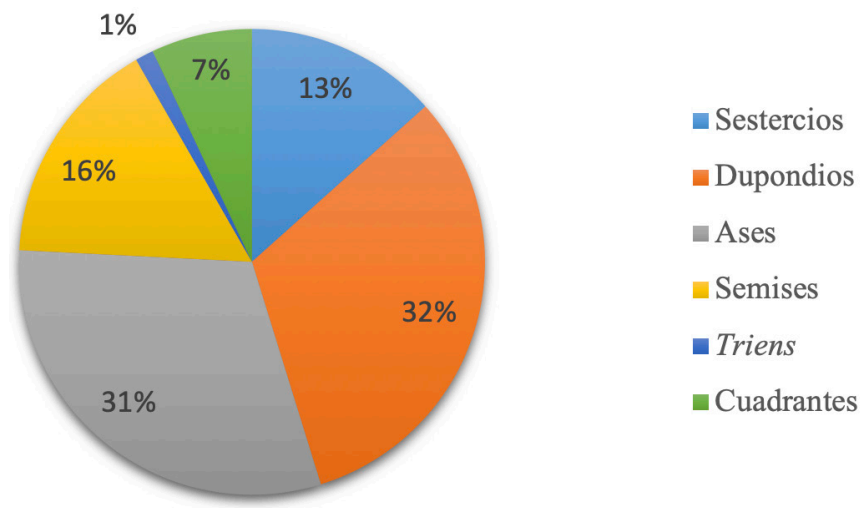

Figura 7. Estimación del del número de ejemplares emitidos según valores por las cecas del África Proconsular, según el total de series distintas emitidas.

En todo caso, frente a estas ciudades-cecas que emitieron un gran número de series de denominaciones de alto valor y que generalmente desarrollaron una producción destacada, hubo otras ciudades en las, en cambio, fueron más numerosas las especies que representaban una menor riqueza, en especial el valor base. El as, de hecho, a nivel general supuso además un porcentaje bastante alto de las emisiones y, lógicamente, de los ejemplares batidos. Esta dinámica se puede observar en Carthago, de cuyas 13 series fabricadas 6 eran ases ${ }^{91}$, en Thapsus, donde se pusieron en circulación 6 emisiones de entre las cuales 4 eran ases ${ }^{92}$, en Sabratha, con 15 emisiones de las que 6 eran ases $^{93}$ y en Oea, de cuyas 14 series 4 eran ases $^{94}$. En Lepcis Magna, en cambio, fueron más numerosas las series que recogían denominaciones fraccionarias.

\section{LA FUNCIÓN ECONÓMICA DE LA MONEDA PROVINCIAL AFRICANA}

La emisión predominante de valores en bronce que, según puede suponerse, debían ser las piezas más cotidianas en los diversos pagos y cobros que habitualmente se efectuaban en las ciudades, y los propios datos sobre el tráfico de estas monedas, puntualizados en los diversos trabajos sobre abastecimiento monetario que se han publicado hasta la

91. RPC I, 745-748 y $754-755$.

92. $R P C$ I, $792-794$ y 797.

93. $R P C$ I, $811,814-815,817-818$ y 820.

94. $R P C \mathrm{I}, 827,829,833$ y 835. 
fecha y que apuntan a una circulación básicamente local/regional del numerario provincial ${ }^{95}$, pueden evidenciar cuál pudo ser el principal desencadenante económico de la fabricación de estas particulares monedas. Al menos puede intuirse cuál fue la función inicial a la que pudieron estar destinadas ${ }^{96}$. Con todo, los mencionados datos parecen sugerir que estas particulares producciones tuvieron como principal objetivo cubrir las carencias de moneda de medio y bajo valor que en algunos momentos sufrieron las provincias del Imperio y que en determinados periodos fueron alarmantemente acusadas. De hecho, estas necesidades de moneda corriente en los pagos y cobros podrían resultar bastante certeras para los primeros instantes de producción de moneda cívica romana, es decir, los años del Segundo Triunvirato y los inicios del Principado, que fueron precisamente los momentos en los que se instituyó el sistema monetario provincial. De este modo debió de ocurrir en la recién creada provincia del África Proconsular, donde el contexto de fuertes demandas locales de numerario pudo haber sido suscitado, al igual que en la mayor parte de territorios, por tres factores principales.

En primer lugar, la creciente infiltración en sus territorios de las estructuras económicas romanas. En este sentido, cabe mencionar que, pese a que esta organización económica al igual que la previamente establecida, no implicó el uso de formas de pago e intercambio totalmente monetarias ${ }^{97}$, sí promovió el uso generalizado de la moneda en determinadas activi-

95. VISONÁ, P.: "Carthaginian coinage in perspective", American Journal of Numismatics, 10,1998.

96. El estudio profundo que desde hace algunos años se viene realizando sobre los contextos arqueológicos en los que han aparecido algunas monedas antiguas apuntan a que el propósito inicial de una emisión monetaria, esto es, el motivo que pudo ocasionar la decisión de su puesta en circulación, que obedeció a motivos que no fueron en todas las ocasiones puramente económicos, y el uso posterior de las mismas, pudieron ser, a veces, muy distintos. Con todo, el papel inicial y el uso social de estas piezas quedaba determinado por su propio contexto, aun siendo utilizadas por individuos pertenecientes a la misma cultura, grupo social e incluso por las mismas personas, quienes podrían otorgarles funciones y significados particularmente diversos dependiendo del ambiente de actuación.

97. Las estructuras económicas romanas se caracterizaron por la convivencia de diversos sistemas de pago y medidas. Estos sistemas no fueron en ningún periodo totalmente privativos, desarrollándose conjuntamente con total armonía en redes de intercambio totalmente mixtas. El grado de desarrollo de unos y otros se difundió de manera muy diferente entre los distintos territorios, pues estaba supeditado al contexto sociocultural en el que se puso en uso. Entre estos sistemas era, por ejemplo, bastante frecuente la costumbre de pago y cobro de productos e impuestos a partir del trueque o la compensación con trabajo, que implicaban medios no totalmente estandarizados ni regulares. Entretanto también tuvo un potente desarrollo el intercambio basado en la utilización del dinero, que era un medio de pago y cobro regular, estandarizado y que tenía un valor adicional intrínseco 
dades. En segundo lugar, la propia tradición en la producción monetaria de estas regiones, acostumbradas a la gestión de una parte mayoritaria de las demandas que emanaban de los usuarios de la zona, fuesen estas más o menos elevadas. En la propia zona de la futura África Proconsular los anteriores usuarios de piezas monetarias disponían de la producción de talleres dispersados por todo el territorio, destacando, en todo caso, las emisiones de la propia Carthago. El alto volumen de producción monetaria de este centro propició incluso que un gran número de sus piezas circularan por amplias zonas del Mediterráneo, especialmente por Sicilia y Cerdeña ${ }^{98}$. De hecho, durante los siglos III-II a. C. las monedas fabricadas por esta ceca fueron las más voluminosas en la zona africana y las únicas producidas de manera regular en bronce. Hasta tal punto debió ser así que los hallazgos monetarios de no pocos centros africanos han evidenciado que pudieron ser precisamente las monedas de Carthago las únicas que en determinados momentos circularon por los mismos ${ }^{99}$.
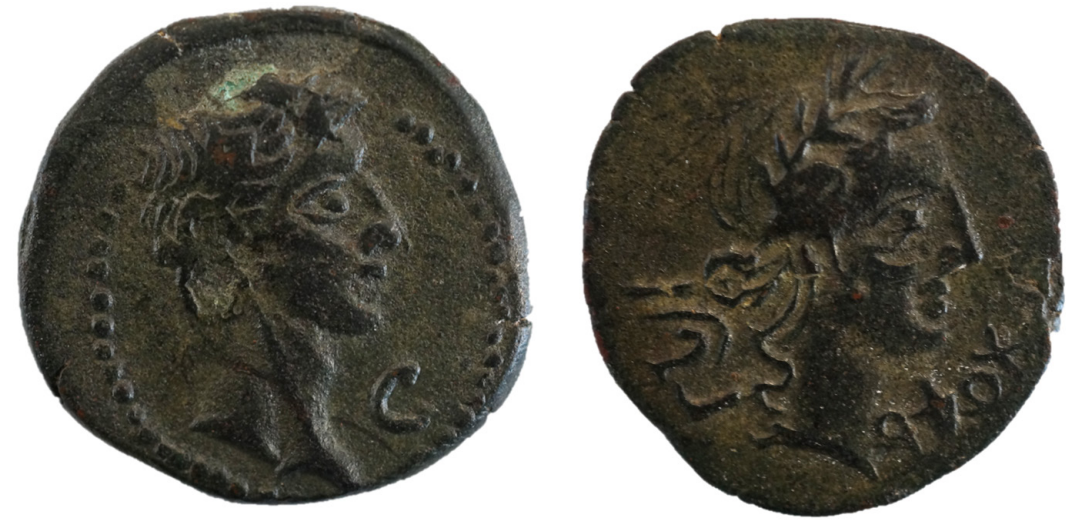

Figura 8. As acuñado en Oea bajo el principado de Augusto (RPC I, 829) (Ashmoleum Museum collection).

reconocido socialmente, de modo que se convertía además en un medio de medida y en un objeto a menudo atesorado. El dinero podía ser no monetario, por ejemplo, algunos lingotes y objetos de metal de cierto valor y productos, a corto plazo poco perecederos, como podrían ser la sal o diversas pieles de animales; y por supuesto, también podría estar constituido por la propia moneda. Esta, además de ser un medio reconocido a nivel institucional, es un instrumento fabricado y emitido por una autoridad competente que intentaba recoger un estándar que fuese socialmente aceptado y que solía dejar una marca que identificase su actuación a partir de la tipología y/o epigrafía presente en su soporte.

98. Visoné, P.: 1998, pp. 1-27.

99. VISONÁ, P.: 1998, p. 21. 
Sin embargo, la producción de Carthago disminuyó a partir del año 146 a. C. ${ }^{100}$. Fue entonces cuando comenzaron a destacar las emisiones de otros talleres. Entre ellos, los más productivos emitieron sobre todo piezas en plata, encontrándose asociados a la mayor parte de los reyes de la zona y/o a las diversas fracciones que apoyaron las causas de los principales políticos romanos que habían desarrollado su actividad en el contexto de las diversas guerras civiles de época tardo-republicanas ${ }^{101}$. Entre estos talleres fue especialmente notorio el de Utica ${ }^{102}$, en el territorio de la futura África Proconsular, pero también el de Siga y Cirta. Junto a ellos, diversas ciudades autónomas pusieron también en circulación algunas series monetarias, fabricadas generalmente en bronce, mucho menos numerosas y cuya circulación fue básicamente local ${ }^{103}$. No obstante, fuesen producidas por unas u otras cecas, todas estas monedas de fabricación africana, no fueron lo suficientemente numerosas como para satisfacer las demandas de los usuarios. Además, aunque es evidente que algunos de los ejemplares acuñados con anterioridad pudieron seguir empleándose años después de su propia acuñación, según pasaba el tiempo las piezas más antiguas comenzaron a deteriorarse y muchas de ellas pudieron extraviarse o retirarse con el objetivo de fundirlas y reacuñarlas. Por este motivo, coincidiendo además con los primeros momentos de expansión del ejército y población civil romanos en territorio africano y, por tanto, con la prematura propagación de las estructuras económicas romanas por el mismo, comenzaron a aumentar en la circulación de la zona algunas monedas de fábrica metropolitana romana. Precisamente el tercer factor que, en párrafos anteriores, se mencionaba como posible causante de las necesidades de moneda de medio y bajo valor que en algunos momentos tuvieron las provincias del Imperio, y entre ellas el África Proconsular, se relaciona con este último hecho.

Aunque inicialmente estas demandas de moneda que planteaban los territorios africanos pudieron ser sufragadas, contando con el apoyo de los talleres indígenas, y la continuada circulación de piezas acuñadas en periodos anteriores, lo cierto es que la creación del sistema administrativo provincial romano pudo implicar que las oficinas metropolitanas recibieran una demanda mucho mayor, viéndose estas seguramente incapacitadas

100. Fischer, B.: Les monnaies antiques d'Afrique du Nord trouvées en Gaule. Paris, 1978, p. 37; VISONÁ, P.: 1998, pp. 22-23.

101. Nicolau Kormikiari, M. C.: 2007, p. 259.

102. Burnett, A., Amandry, M. \& Ripollès, P. P.: 2006, p. 190.

103. AleXandropoulos, J.: 2007; Kormikiari, M. C.: Norte da Africa autóctone do século III ao I a. C.: as imagens monetárias reais berberes. Sao Paulo, 2000, pp. 276-304. 
para aprovisionar a regiones tan amplias. Con todo, resulta evidente que estos talleres estaban acostumbrados a responder a unos requerimientos de numerario mucho más reducidos. Por esta razón, aunque lógicamente estas oficinas romanas se vieron obligadas a aumentar su producción, esta no fue suficientemente amplia como para abastecer todos los territorios. Y es que no puede olvidarse que en el año 82 a. C. se produjo la paralización en la acuñación de bronces por parte de los talleres oficiales metropolitanos ${ }^{104}$, los cuales no reanudaron su actividad hasta el gobierno de Julio César ${ }^{105}$.
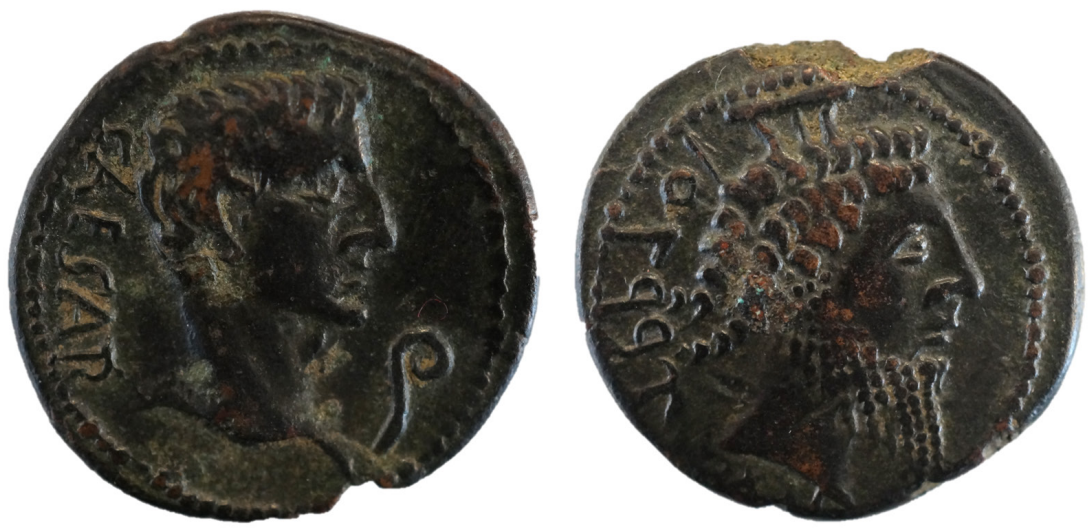

Figura 9. As acuñado en Sabratha bajo el principado de Augusto (RPC I, 815) (Ashmoleum Museum collection).

Todas estas circunstancias promovieron que en los primeros momentos de producción de numerario provincial algunos talleres indígenas africanos previos conservaran su actividad, ya incluida en el nuevo sistema de acuñación monetaria. Además, mientras otros muchos se clausuraron, se produjo la apertura de nuevas oficinas locales o la reapertura de centros

104. BlázQuez Cerrato, M. C.: «Emisiones y circulación monetaria en Hispania en época transicional (72-27 a. C.)", en García-Bellido, M. P., Mostalac, A. y Jiménez, A. (eds.): Del imperium de Pompeyo a la auctoritas de Augusto. Homenaje a Michael Grant. Madrid, 2008, p. 272; Giard, J. B.: "La pénurie de petite monnaie en Gaule au début du HautEmpire", Journal des Savants, 2, 1975, pp. 81-102; MAUReL, R.: "Monnaies divisionaires de fortune de la numismatique antique de Nîmes", Acta Numismática, V, 1975, p. 15.

105. Padilla, A.: "Las monedas de Augusto. Un acercamiento a la política monetaria de finales de la República y comienzos del Imperio", en González Román, C. y Pociña, A. (eds.): Augusto, Dos mil años después. Contribuciones para su estudio. Granada, 2017, p. 169. 
clausurados décadas atrás. De hecho, a juzgar por los datos relativos a la fabricación de las distintas series monetarias, estos talleres reabiertos en el África Proconsular debieron ser mucho más productivos que los anteriores.

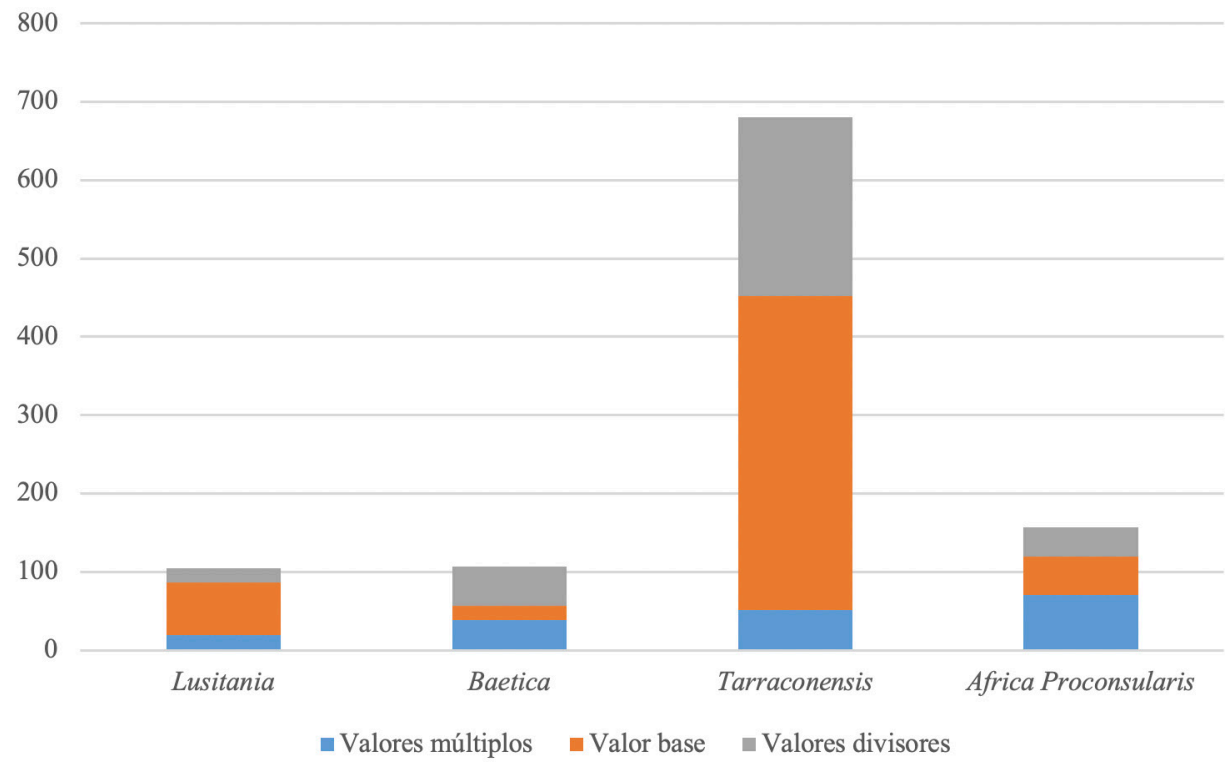

Figura 10. Estimación del número de ejemplares emitidos según valores por las cecas de algunos territorios del Imperio romano, según provincia y series distintas emitidas ${ }^{106}$.

Ahora bien, pese a todo, como se ha indicado con anterioridad, la escala de producción de la mayor parte de cecas provinciales africanas fue muy escasa. Además, los datos sobre emisión monetaria de los que actualmente se dispone apuntan a que la producción de moneda en cada provincia fue enormemente dispar. En este sentido, es necesario advertir que cualquier análisis de cuantificación monetaria presenta considerables limitaciones. En primer lugar, porque es muy difícil cuantificar cómo pudo afectar la circulación de otras piezas monetarias (indígenas y romanas de previa acuñación e imperiales) en la producción de moneda provincial

106. La realización de parte de este gráfico se ha fundamentado en un trabajo básico sobre el monetario hispano (RIPOllès, P. P., MuÑOz, J. y Llorens, M. M.: "The original number of diez used in the Roman Provincial Coinage of Spain", en Actes du XIe Congrès International de Numismatique (Bruxelles, 1991), vol. I. Louvain-la-Neuve, 1993, pp. 315324), cuyos datos hemos revisado y actualizado a partir de la información contenida en los catálogos de referencia. 
de cada territorio. Y, en segundo lugar, porque estos datos parte de una estadística sometida a la casualidad concerniente a cualquier hallazgo arqueológico y por tanto se fundamentan en la eventualidad relacionada con su propia pérdida y su actual conocimiento. No obstante, resulta evidente que los datos disponibles en la actualidad pueden ser harto ilustrativos. Llama la atención que, entre las provincias occidentales, la que mayor producción registró, es decir la Citerior Tarraconensis, pusiera en circulación un numero de series relativas a valores múltiplos menor que el verificado en el África Proconsular. Así lo verifican los datos disponibles. Resulta también llamativo que en la provincia africana, pese a producirse un mayor número de emisiones, las series de divisores fuera menor que en la Baetica y las relacionadas con el as menos numerosas que en la Lusitania.

Pero si las cifras constatadas en lo referente a la producción de cada provincia son dispares, también lo son por lo que respecta al volumen de acuñaciones registrado en las diversas cecas africanas. Entre ellas, hubo algunas que se caracterizaron por la fabricación masiva de denominaciones de alto valor. Así ocurrió en Sicca, Utica y Paterna, en la zona septentrional, y Hadrumetum y Thaena, en la zona central. En cambio, otras destacaron por la emisión de denominaciones base, como se observa en la producción registrada en Carthago, en la región norte, en Leptis Minus y Thapsus, en el centro, y en Sabratha y Oea, en el sur. En Lepcis Magna, sin embargo, las emisiones más numerosas se relacionaban con valores divisores. Es interesante, en este sentido, también precisar que durante el Principado, en todas las regiones de la provincia, se verifica la existencia de talleres con producciones dispares, de modo que ninguna de las zonas presenta una producción que despunte con respecto al resto, ni en número de emisiones ni en volumen de series por valores. Al menos así ocurrió en los años iniciales y de desarrollo principal de la moneda provincial, pues a partir del imperio de Tiberio sí puede constatarse una mayor producción en la zona norte, especialmente en talleres como los de Carthago, Paterna y, sobre todo, Utica.

Esta heterogénea producción y los datos sobre el exiguo volumen general permite descartar, tal y como ha deducido P. P. Ripollès para las acuñaciones hispanas, que las africanas fuesen producidas con el objetivo de satisfacer necesidades lo suficientemente elevadas, como podrían ser las que emanaban del propio Estado romano y, entre ellas, por ejemplo, la remuneración del ejército ${ }^{107}$. Con todo, aunque algunos hallazgos arqueológicos corroboran el uso de determinadas piezas provinciales por parte de estas instituciones, en especial a partir de su aparición en algunos

107. RIPOllès, P. P.: 2010, p. 29. 
campamentos romanos, la adquisición de las monedas pudo haberse debido a un proceso de extendido empleo mercantil de las mismas, actuando sobre todo como divisas de cambio en algunas transacciones.

Debe recordarse, en este sentido, aunque posteriormente se hará una referencia más extendida sobre este hecho, que no en todos los intercambios se utilizaban únicamente piezas de alta riqueza, como podrían ser las que por lo general eran empleadas para los pagos a los miembros de los organismos centrales. Resulta, a tenor de ello, también interesante tener en consideración, tal y como ha apuntado C. Howgego y, recuerda E. García Vargas, que en ocasiones el uso financiero inicial de una determinada serie monetaria puede confundirse con su uso comercial posterior ${ }^{108}$, ya que la puesta en circulación de una pieza por parte de una determinada ciudad, aun teniendo como principal objetivo financiar los gastos de la misma, implicaba su introducción en el propio mercado. Así pues, según se deduce, los motivos que hicieron posible la producción provincial del África Proconsular se correspondieron con necesidades mucho más escuetas que las vinculadas exclusivamente al poder central, como eran las relacionadas con los órganos locales y los propios habitantes del centro. Pudieron ser, en este caso, suficientes como para satisfacer algunas de las demandas más cotidianas que estos requerían ${ }^{109}$.Habida cuenta de lo señalado en párrafos anteriores, puede concluirse que la incorporación de moneda en bronce en la masa monetaria utilizada en estos centros debió optimizar el propio uso de la divisa de mayor valor, es decir, aquella fabricada en plata, generando un sistema monetario bastante complejo dado que se caracterizaba por el empleo de un número de piezas de alta y baja riqueza bastante considerable. Según se intuye, de este modo debió de ocurrir en lugares donde las denominaciones emitidas fueron especialmente variadas, como fue, en efecto, en la propia África Proconsular. A tenor de ello, es preciso tener presente que, como se ha indicado en líneas anteriores, resulta bastante verosímil deducir que no en todas las actividades financieras y mercantiles podían utilizarse piezas de tan alta riqueza. Entre ellas, por ejemplo, se encontraban las relativas a la moneda de plata o al numerario en bronce de altas denominaciones. Este complejo uso de la moneda pudo relacionarse tanto con el pago y cobro de los impuestos, rentas, salarios y créditos $^{110}$, como con la adquisición y venta de bienes y servicios por parte de las ciudades y sus propios habitantes. A fin de cuentas, la presencia de

108. García Vargas, E.: 2004, p. 10; Howgego, C.: "Coin circulation and the Roman economy", Journal of Roman Archaelogy, 7, 1994 p. 7.

109. BuRnetT, A.: 1993, p. 148.

110. Howgego, C.: 1992 , pp. 22-30. 
una conveniente cantidad de monedas de menor valor era indispensable para el desarrollo de los cambios en las transacciones.

Según evidencian los propios datos de emisión monetaria por valores que hemos detallado, en la provincia objeto de estudio, hasta el más insignificante pago o cobro, esto es, en el que se utilizaran piezas con un escaso valor, pudo encontrarse monetizado, especialmente en los momentos principales de acuñación africana; por más que se acepte el posible uso de otras formas de pago y cobro, no exclusivamente monetarias. Pero también lo hubieron de estar las financiaciones de mayor valor, como serían, por ejemplo, los pagos y cobros de servicios cívicos por parte de los órganos locales, para los cuales posiblemente pudieron estar destinadas algunos de los numerosos sestercios y dupondios de fábrica africana.

\section{CONSIDERACIONES FINALES}

Teniendo en cuenta estas circunstancias, una hipótesis bastante verosímil, pero que, en todo caso, no puede presentarse como totalmente segura, es que en una primera fase la producción de cada una de las cecas africanas se desarrollara en función de los requerimientos que el territorio en el que estaba ubicada iba recibiendo, de modo que los posibles excedentes de producción generados se dirigieran al aprovisionamiento de otros centros cercanos. Las demandas de monetario, según planteamos, podrían ser en este caso tanto locales como regionales, y se relacionarían también con el posible empleo de monedas acuñadas con anterioridad y de ejemplares imperiales. De estar en lo cierto, podría apuntarse a la existencia de verdaderas regiones monetarias, en las que se constatase la actividad de algunos talleres caracterizados por la notable puesta en circulación, e incluso especialización en la fabricación, de un determinado tipo de valores. Siendo así, podría concluirse que en los principales momentos de acuñación provincial, esto es, a lo largo de la etapa augustea, en el África Proconsular existieron algunas regiones caracterizadas por una producción y uso de moneda cívica bastante homogéneo y basado, al menos en parte, en el autoabastecimiento. En este sentido, debe recordarse que como es bien conocido y así lo han advertido recientemente autores como C. Howgego, el grado de uso de la moneda no fue totalmente homogéneo en el Imperio romano, pues debió variar según la zona y la época en la que se hubo de desarrollar ${ }^{111}$. Esto pareció ser así teniendo en cuenta los

111. Howgego, C.: 1992, p. 19. 
datos referidos a las emisiones africanas, planteándose un escenario de fabricación de moneda bastante singular.

Puede constatarse una primera región en la zona norte, donde las cecas se asociaban a ciudades privilegiadas y en la que despuntaron las emisiones augusteas de Carthago. Precisamente, fue esta zona la que tras el inicio del imperio de Tiberio desarrolló un volumen de producción que destacó sobre el resto, especialmente en talleres como el de Utica. La segunda región que podría contemplarse estaría situada en la costa central de la provincia. A la vista de los resultados de nuestra investigación, la producción de esta segunda región debió ser especialmente prolífera durante los años del Principado, destacando las emisiones de talleres como Hadrumetum, Leptis Minus y Thaena, mientras que la del resto fue mucho menos voluminosa. Y, finalmente, se verifica la existencia de una tercera región, en la costa meridional, caracterizada por una producción más constante que lo observado con respecto a los otros territorios y en la que el volumen de emisión de cada una de las cecas fue mucho más homogéneo.

\section{Bibliografía}

AlEXANDROPOlous, J.: "La romanisation des monnayages antiques de l'Afrique du Nord orientale: Analyse de quelques jalons", en GARCíaBellido, M. P. y Callegarin, L. (coords.): Los cartagineses y la monetización del Mediterráneo Occidental. Madrid, 2000, pp. 43-52.

AleXandropolous, J.: Les monnaies de l'Afrique antique. 400 av. J. C.-40 ap. J. C. Toulouse-Le Mirail, 2007.

AleXANDROpolous, J.: «Monnaie», Encyclopédie berbère, 32, 2010, pp. 50685076.

Amandry, M.: "Le monnayage augustéen de Leptis Minor (Byzacène)", Schweizer Münzblätter, 33-37, 1983, pp. 11-14.

Amandry, M.: "Notes de numismatique africaine II", Revue Numismatique, 28, 1986, pp. $72-82$.

Amandry, M.: "Tingi (32 av. J.-C.-29 après)", en Huvelin, H., Christol, M. et Gautier, G. (eds.): Mélanges de numismatique: offerts à Pierre Bastien à l'occasion de son 75e anniversaire. Wetteren, 1987, pp. 1-14.

AmANDRY, M.: "Notes de numismatique africaine III", Revue Numismatique, 30, 1988, pp. 114-119.AMANDRY, M.: «Notes de numismatique africaine V", Revue de Numismatique, 32, 1990, pp. 56-71.

Amandry, M.: "Notes de numismatique africaine. VI. 8. Achulla", Revue de Numismatique, 34, 1992, pp. 46-53. 
Amandry, M.: "Le monnayage de Thaena/Thena", en Kancel, S. (ed.): Africa du Nord Antique et médievale. Numismatique, langues, écritures et arts du peregrina, spécifité des arts figurés. Actes di VIIe coll. Int. Sur l'Histoire et l'Archéologie de l'Afrique du Nord. Paris, 1995, pp. 52-65.

AmAndry, M.: "Une monnaie inédite d'Auguste frappé à Colonia Iulia Paterna", en Delrieux, F. et Kayser, F. (eds.): Des déserts d'Afrique au pays des Allobroges. Mélanges offerts à Francois Bertrandy. Chambéry, 2010, pp. 13-19.

AmANDry, M. et BARRANDON, J.-N.: "La genèse de la réforme monétaire augustéenne", en García-Bellido, M. P., Mostalac, A. y Jiménez, A. (eds.): Del imperium de Pompeyo a la auctoritas de Augusto. Homenaje a Michael Grant. Madrid, 2008, pp. 209-233.

Amandry, M., Burnett, A., Hostein, A., Mairat, J., Ripollès, P. P. \& Spoerri Butcher, M.: Roman provincial coinage. Supplement 5, Oxford, 2019.

Arévalo, A.: "La moneda provincial romana de Hispania en el Museo de Cádiz", en La colección de moneda del Museo de Cádiz. Sevilla, 2005, pp. 49-70.

BlÁzQuez Cerrato, M. C.: "Emisiones y circulación monetaria en Hispania en época transicional (72-27 a. C.)", en García-Bellido, M. P., Mostalac, A. y Jiménez, A. (eds.): Del imperium de Pompeyo a la auctoritas de Augusto. Homenaje a Michael Grant. Madrid, 2008, pp. 259-278.

BurnetT, A.: Coinage in the Roman World. London, 1987.

BurnetT, A.: "Roman Provincial Coins of the Julio-Claudians", en Essays in Honour of R. Carson and G. K. Jenkins. London, 1993, pp. 145-153.

BuRNETT, A.: "Monetary union in the Roman Empire", Numismatikai közlöny, 100-101, 2001-2002, pp. 15-20.BurnetT, A.: "The Augustan Revolution seen from the mints of the province", Journal of Roman Studies, 101, 2011, pp. 1-30.

Burnett, A, Amandry, M., Carradice, I., Ripollès, P. P. \& Spoerri Butcher, M.: Roman provincial coinage. Supplement 3. New York, 2014 (citado como RPC-S3).

Burnett, A., Amandry, M., Hostein, A., Mairat, J., Ripollès, P. P. \& Spoerri Butcher, M.: Roman provincial coinage. Supplement 4. Oxford, 2017 (citado como RPC-S4).

Burnett, M., Amandry, M. \& Ripollès, P. P.: Roman Provincial Coinage, vol. I. From the death of Caesar to the death of Vitellius (44BC-AD 69). London-Paris, 1992 (citado como RPC).

Burnett, A., Amandry, M. \& Ripollès, P. P.: Roman provincial coinage. Supplement 1. London-Paris, 1998 (citado como RPC-S).

Burnett, A., Amandry, M., Ripollès, P. P. \& CARradice, I.: Roman provincial coinage. Supplement 2. Valencia, 2006 (citado como RPC-S2). 
Butrey, T. V.: "Calculating ancient coin production: fact and fantasies", Numismatic Chronicle, 153, 1993, pp. 335-331.

Butrey, T. V.: "Calculating ancient coin production II: why it cannot be done", Numismatic Chronicle, 154, 1994, pp. 341-352.

Callegarin, L., Frey-Kupper, S. et Geneviève, V.: "Les monnayages provinciaux: les provinces occidentales", en ARNold-Biucchi, C. \& Caccamo Caltabiano, M. (eds.): A survey of numismatic reserach 20082013, Taormina, 2015, pp. 220-227.

CAMPO, M.: "Las monedas de Claudio de la ceca de Ebusus", Nvmisma, 1976, pp. 138-143.

CAMPo, M.: Las monedas de Ebusus. Barcelona, 1976, pp. 48-49.

Fischer, B.: Les monnaies antiques d'Afrique du Nord trouvées en Gaule. Paris, 1978.

GARCía VARGAS, E.: "Aspectos económicos de la moneda romana imperial", en La moneda de l'Imperi romà. VIII Curs d'Història monetària d'Hispània (25 i 26 de noviembre de 2004. Barcelona, 2004, pp. 9-25.

GiARD, J. B: "Pouvoir central et libertés locales. Le monnayage en bronze de Claude avant 50 après J.-C.", Revue Numismatique, XII, 1970, pp. 33-61.

GiARD, J. B.: "La pènurie de petite monnaie en Gaule au début du HautEmpire", Journal des Savants, 2, 1975, pp. 81-102.

Grant, M.: From Imperium to Auctoritas. Cambridge, 1946.

GYÖRI, V.: "The lituus and augustan provincial coinage", Acta antiqua Academiae Scientiarum Hungaricae, 55, 2015, pp. 45-60.

Howgego, C.: "The supply and use of money in the Roman World 200 B.

C. to A. D. 300", Journal of Roman Studies, 82, 1992, pp. 1-31.

Howgego, C.: "Coin circulation and the Roman economy", Journal of Roman Archaelogy, 7, 1994, pp. 5-31.

Howgego C.: La storia antica attraverso le monete. Roma, 2002.HuRlet, F. et Suspène, A.: "Le proconsul et le Prince. À propos des portraits monétaires des proconsuls d'Africa et d'Asia sous le Principat d'Auguste", en BAUdrY, R. et Destephen, S. (ed.): La societé romaine et ses élites. Hommages à Elisabeth Deniaux. Paris, 2012, pp. 73-90.

Hurtado Mullor, T.: Las emisiones monetarias de la Colonia Victrix Iulia Lepida-Celsa. Valencia, 2013.

Jenkins, G. K: Sylloge Nummorum Graecorum. Danish National Museum, North Africa, Syrtica-Mauretania. Copehangen, 1969.

Kormikiari, M. C. N: Norte da Africa autóctone do século III ao I a. C.: as imagens monetárias reais verberes. Sao Paulo, 2000.

MAZARD, J.: Corpus Nummorum Numidiae Mauretaniaque. Paris, 1955. 
Mattingly, H.: "The Provincial and Local Coinage of the Early Empire", en Roman Coins. London, 1977, pp. 188-207.

MAUREL, R.: "Monnaies divisionaires de fortune de la numismatique antique de Nîmes", Acta Numismática, V, 1975, pp. 15-26.

MüLler, L.: Numismatique de l'ancienne Afrique, II: les monnaies de la Syrtique, de la Byzacène et de la Zeugitane. Bologna, 1861.

Nicolau Kormikiari, M. C: "Norte da África na antiguidade: os reis berberes númidas e suas iconografías monetarias", Revista do Museo de Arqueologia e Etnologia São Paulo, 17, 2007, pp. 251-292.

Padilla, A.: "Las monedas de Augusto. Un acercamiento a la política monetaria de finales de la República y comienzos del Imperio", en González Román, C. y Pociña, A. (eds.): Augusto, Dos mil años después. Contribuciones para su estudio. Granada, 2017, pp. 167-192.

RIPOllès P. P.: Las acuñaciones provinciales de Hispania. Madrid, 2010.

Ripollès, P. P: "Ancient Iberian Coinage", Documentos Digitales de Arqueología, 2, 2013.

Ripollès, P. P., Muñoz, J. y Llorens, M. M.: "The original number of diez used in the Roman Provincial Coinage of Spain", en Actes du XIe Congrès International de Numismatique (Bruxelles, 1991), vol. I. Louvain-la-Neuve, 1993, pp. 315-324.

SAVIO, A.: "La numismatica e i problemi quantitativi: in torno al calcolo del volume delle emisioni, Rivista italiana di Numismatica, 98, 1997, pp. $11-48$.

SutHerland, C. H. V.: Romans in Spain. London, 1939.VIsonÁ, P.: "Carthaginian coinage in perspective", American Journal of Numismatics, 10,1998, pp. 1-27. 